Benha Veterinary Medical Journal 39 (2020) 175-179

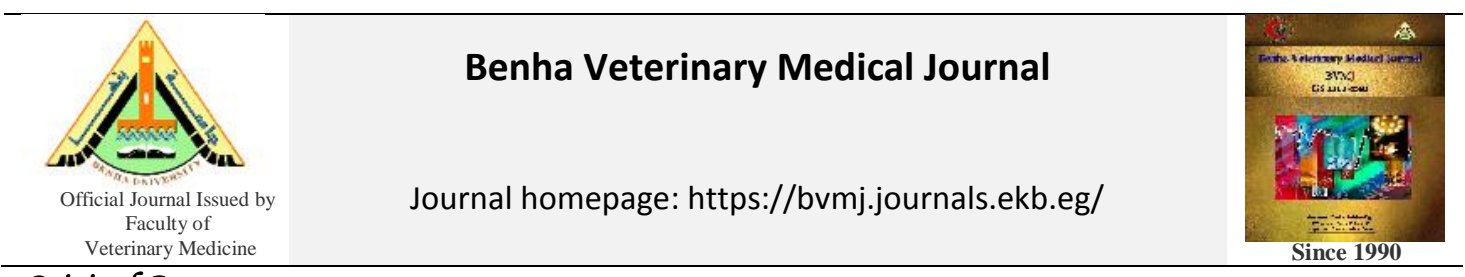

Original Paper

\title{
Mycotoxin residues in some fish products
}

Saad M. S., Hassan M. A., Hassanien F. S, Awud A. A.

Food Control Dept. Faculty of Veterinary Medicine, Benha University

\section{ARTICLE INFO}

\section{Keywords}

Aflatoxin

Fish products.

Ochratoxin

Smoked herring

Received 18/08/2020

Accepted 14/09/2020

Available On-Line

$01 / 10 / 2020$

\begin{abstract}
A grand of 90 random samples represented by smoked herring, canned sardines and frozen fish fillets (30 of each) were collected during their validity period from different areas in Menoufia Governorate to evaluate their mycotoxins quality. It was found that the average values of aflatoxin B1/kg in the examined fish products samples were $51.63 \pm 4.82 \mu \mathrm{g} / \mathrm{kg}$ for smoked herring, $33.14 \pm 2.98 \mu \mathrm{g} / \mathrm{kg}$ for canned sardine and $19.76 \pm 2.21 \mu \mathrm{g} / \mathrm{kg}$ for frozen fish fillets. The mean values of aflatoxin $\mathrm{B} 2 / \mathrm{kg}$ in the examined fish product samples were $37.29 \pm 3.75 \mu \mathrm{g} / \mathrm{kg}$ for smoked herring, $20.81 \pm 3.02 \mu \mathrm{g} / \mathrm{kg}$ for canned sardine and $14.57 \pm 1.90 \mu \mathrm{g} / \mathrm{kg}$ for frozen fish fillets. The average value of aflatoxin $\mathrm{G} 1 / \mathrm{kg}$ was 25.06 $\pm 3.18 \mu \mathrm{g} / \mathrm{kg}$ for smoked herring, $14.42 \pm 1.96 \mu \mathrm{g} / \mathrm{kg}$ for canned sardine and $9.65 \pm 1.32 \mu \mathrm{g} / \mathrm{kg}$ for frozen fish fillets. The average values of aflatoxin $\mathrm{G} 2 / \mathrm{kg}$ in the examined fish products samples were $16.22 \pm 1.39 \mu \mathrm{g} / \mathrm{kg}$ for smoked herring, $11.29 \pm 0.92 \mu \mathrm{g} / \mathrm{kg}$ for canned sardine and $4.46 \pm 0.53 \mu \mathrm{g} / \mathrm{kg}$ for frozen fish fillets. Whereas the mean values of Ochratoxin $\mathrm{A} / \mathrm{kg}$ were $6.52 \pm 0.74 \mu \mathrm{g} / \mathrm{kg}$ in the examined smoked herring samples, $5.60 \pm 0.61 \mu \mathrm{g} / \mathrm{kg}$ in the examined samples of canned sardine and $3.24 \pm 0.39 \mu \mathrm{g} / \mathrm{kg}$ in frozen fish fillets. Moreover, it was found that aflatoxin B1 was the predominant mycotoxin that detected in the examined fish products samples particularly smoked herring.
\end{abstract}

\section{INTRODUCTION}

Fish and fish products are necessary for human as they are an important source of high-quality protein. The increasing demand for aquatic products returns to the high nutritional benefits of these products as they are rich in omega 3 and polyunsaturated fatty acids. In addition to the nutritional value of fish and fish products, they are also important as a foreign exchange earner in global trade for many world countries. Fish is more subjected to contamination as it is soft and easily damaged so it must be subjected to some forms of processing or preservation otherwise, it will become unfit for human consumption. The fish may be still subjected to many forms of spoilage even after it has been processed particularly if traditional methods have been used (Shewan, 2000).

The fish product can make reabsorption of moisture from surrounding environment during storage and this enhance the growth of microorganisms and presence of Aspergillus spp, Rhizopus spp and Penicillium (Ayolabi and Fagade, 2010). The market place can be a source of contamination for the fish product due to bad hygiene, insufficient cleaning or preservation in open trays without coverage that allow settling of dust and fungal spores on the product and so occurrence of fungal invasion, production of toxins and spoilage of the product (Fredrick Sam et al., 2016). Mycotoxins have a great ability to penetrate human and animal cells and affect the cellular genome where they can cause a major mutagenic change in the nucleotide sequence that may result in strong and permanent defects in the genome (Adam et al., 2017).Mycotoxins are known worldwide as fungus produced toxins and consumption of food contaminated with mycotoxins leads to a plethora of harmful responses from acute toxicity to many persist and health disorders with lethal effect ( $C^{\curlyvee}$ Olovic et al., 2019). The inclusion of vegetal raw materials in feed for fish farming may increase the risk of mycotoxin occurrence in feed and also in edible tissues from contaminated fish feed due to the carry-over to muscle portions (Tolosa et al., 2019)

Aflatoxins are a type of toxic secondary metabolites that can be produced by Aspergillus flavus and Aspergillus parasiticus. They have a great health and economic importance. Aflatoxin B1 is a well-known Hepatocarcinogen that is classified as class I human carcinogen by the International Agency for Research in Cancer so that its bioavailability must be reduced to maintain human health (Amnah, 2013). Ochratoxins (OTA) constitute a great threat to animal and human health. They can cause sub chronic and chronic effect on human while acute toxicity of OTA in human is rarely reported. In animals, OTA has been to have hepatotoxic, nephrotoxic, immunotoxic and teratogenic effect (Richard, 2007). Therefore, the current study is applied for detection of Aflatoxin (B1, B2, G1 and G2) and Ochratoxin A in the examined samples of smoked herring, canned sardine and frozen fish fillets and their public health effect. 


\section{MATERIAL AND METHODS}

\subsection{Collection of samples:}

About 90 random samples of fish products represented by smoked herring, canned sardines and frozen fish fillets (30 of each) were collected during their validity period from different markets in Menoufia governorate. All samples were labeled and separately kept in a sterile plastic bag as well as preserved in an ice box. All the collected samples were transferred to the laboratory without delay and examined for detection of their contents of mycotoxins either aflatoxins (B1, B2, G1 \& G2) or Ochratoxin A to determine their edibility for human consumption.

Standards:

Standard and Blank aflatoxins B1, B2, G1 and G2 used in the current study were purchased from Sigma-Aldrich, Steinheim, Germany.

Apparatus:

High performance liquid chromatography (HPLC) used for aflatoxin determination was an Agilent 1100 HPLC system, Agilen Technologies, Waldbronn, Germany, equipped with quaternary pump model G 1311A, UV detector (Model G $1314 \mathrm{~A}$ ) set at $254 \mathrm{~nm}$ wavelength.

2.2. Standard Aflatoxins B1 (AFB1), B2 (AFB2), G1 (AFG1), G2 (AFG2) and Ochratoxin A (OTA) solutions:

The stock standard solutions of AFB1, AFB2, AFG1, AFG2 and OTA were prepared by dissolving the solid standard in benzene as described by AOAC (2000). All the solutions were packed in amber vials at $-18{ }^{\circ} \mathrm{C}$.

2.3. Quantitative determination of aflatoxins according to (European Council, 2006):

Sample extraction:

In a blender, $50 \mathrm{~g}$ of the prepared homogenized sample were mixed with $100 \mathrm{ml}$ of acetone and $100 \mathrm{ml}$ of water for $10 \mathrm{~min}, 10 \mathrm{~g}$ of diatomaceous earth were added and stirred gently for $5 \mathrm{~min}$ then filtered through fast filtering Whitman No. 1 filter paper.

Accurately, $0.01 \mathrm{ml}$ of the filtrate were transferred to 500 $\mathrm{ml}$ wide mouth glass stopper Erlenmeyer volumetric flask and mixed with $50 \mathrm{ml}$ of $5 \% \mathrm{NaCl}$ and $50 \mathrm{ml}$ of hexane then shaken gently on a mechanical shaker (IKA, GmbH, Germany) for $5 \mathrm{~min}$ at $2400 \mathrm{rpm}$. The hexane layer was discarded. Next, $50 \mathrm{ml}$ of $5 \% \mathrm{NaCl}$ and $150 \mathrm{ml}$ of chloroform $(3 \times 50 \mathrm{ml})$ were added to the aqueous layer and shaken gently for 5 min each time. The chloroform layer was collected from the three extractions, dried over anhydrous sodium sulphate and evaporated using rotary evaporator. The residues were re-dissolved in $1 \mathrm{ml}$ chloroform.

2.4. HPLC determination according to Galvano et al. (2001):

The determination of each aflatoxin was carried out with HPLC at wavelength 365 and $440 \mathrm{~nm}$ for excitation and emission, respectively. The mobile phase was composed of toluene, ethyl acetate, formic acid and methanol $(90: 5: 2.5: 2.5, \mathrm{v} / \mathrm{v})$ which pumped with constant flow at 1.0 $\mathrm{ml} / \mathrm{min}$. Actually, $20 \mathrm{ml}$ of the reconstituted sample were injected in the HPLC at $24{ }^{\circ} \mathrm{C}$ to achieve the optimum resolution of aflatoxins.

2.5. Quantitative estimation of ochratoxin A:

Extraction procedure for ochratoxin A:

The samples were extracted according to the method described by Toscani et al. (2007) with little modifications.
The sample $15 \mathrm{~g}$ was blended for $15 \mathrm{~min}$ in $50 \mathrm{ml}$ of aceto nitrile - water $(45: 05, \mathrm{v} / \mathrm{v})$, using high speed blending and then the extract was filtered through filter paper. $5 \mathrm{ml}$ of the filtrate was mixed with $50 \mathrm{ml}$ of phosphate buffer saline (PBS) and filtered through a glass microfiber.

Accurately, $10 \mathrm{ml}$ of the filtrate was passed through immunoaffinity columns. OTA was eluted from the column by passing $1.5 \mathrm{ml}$ of methanol (HPLC grade) and collected in a vial. The eluted was evaporated until dryness at $40{ }^{\circ} \mathrm{C}$ and residues were re-dissolved in $1 \mathrm{ml}$ of mobile phase i.e. acetonitrile: water: acetic acid (47/51/2, v/v/v) for HPLC analysis.

\subsection{Statistical analysis:}

The obtained results were analyzed statistically by application of Analysis of variance (ANOVA) test according to Feldman et al. (2003).

\section{RESULTS}

Results achieved in table (1) showed that aflatoxin B1 was detected in $43.33 \%, 30 \%$ and $20 \%$ of the examined samples of smoked herring, canned sardine and frozen fish fillets, respectively. Totally, $31.11 \%$ of the examined samples of fish products were contaminated with aflatoxin B1. Whereas the concentrations of aflatoxin B2 are $26.67 \%$, $20 \%$ and $16.67 \%$ for smoked herring, canned sardine and frozen fish fillets, respectively. Totally, $21.11 \%$ of the examined samples of fish products were contaminated with aflatoxin B2. Aflatoxin G1 occurred in a level of $20 \%$ for smoked herring samples, $13.33 \%$ for canned sardine and $10 \%$ for frozen fish fillets. Totally $14.44 \%$ of the examined fish products samples were proved to be contaminated with aflatoxin G1. Aflatoxin G2 showed the following incidence in the examined samples of smoked herring, canned sardine and frozen fish fillets $(13.33 \%, 13.33 \%$ and $6.67 \%)$ respectively. Totally, $11.11 \%$ of the examined fish product samples were contaminated with aflatoxin G2.

Table 1 Incidence of aflatoxins (B1, B2, G1 and G2) in the examined fish product samples $(n=30)$.

\begin{tabular}{lccccc} 
Fish products & AFB1 (\%) & AFB2 (\%) & AFG1 (\%) & AFG2 (\%) \\
\hline Smoked herring & 43.33 & 26.67 & 20 & 13.33 \\
Canned sardines & 30 & 20 & 13.33 & 13.33 \\
Frozen fish fillets & 20 & 16.67 & 10 & 6.67 \\
Totally & 31.11 & 21.11 & 14.44 & 11.11
\end{tabular}

Table (2) revealed that the average values of aflatoxin $\mathrm{B} 1 / \mathrm{kg}$ in the examined fish products samples were $51.63 \pm 4.82 \mu \mathrm{g} / \mathrm{kg}$ for smoked herring, $33.14 \pm 2.98 \mu \mathrm{g} / \mathrm{kg}$ for canned sardine and $19.76 \pm 2.21 \mu \mathrm{g} / \mathrm{kg}$ for frozen fish fillets. The mean values of aflatoxin $\mathrm{B} 2 / \mathrm{kg}$ in the examined fish product samples were $37.29 \pm 3.75 \mu \mathrm{g} / \mathrm{kg}$ for smoked herring, $20.81 \pm 3.02 \mu \mathrm{g} / \mathrm{kg}$ for canned sardine and $14.57 \pm 1.90 \mu \mathrm{g} / \mathrm{kg}$ for frozen fish fillets. The average value of aflatoxin $\mathrm{G} 1 / \mathrm{kg}$ was $25.06 \pm 3.18 \mu \mathrm{g} / \mathrm{kg}$ for smoked herring, $\quad 14.42 \pm 1.96 \mu \mathrm{g} / \mathrm{kg}$ for canned sardine and $9.65 \pm 1.32 \mu \mathrm{g} / \mathrm{kg}$ for frozen fish fillets. The average values of aflatoxin $\mathrm{G} 2 / \mathrm{kg}$ in the examined fish products samples were $16.22 \pm 1.39 \mu \mathrm{g} / \mathrm{kg}$ for smoked herring, $11.29 \pm 0.92$ $\mu \mathrm{g} / \mathrm{kg}$ for canned sardines and $4.46 \pm 0.53 \mu \mathrm{g} / \mathrm{kg}$ for frozen fish fillets.

Table (3) detected that about $33.33 \%$ of the examined smoked herring samples, $23.33 \%$ of canned sardine and $16.67 \%$ of frozen fish fillets are unaccepted due to the incidence of AFB1 according to the permissible limits of 
FDA (2004) which stated that fish and fish products should be free from mycotoxins. Also, $23.33 \%$ of the examined smoked herring samples, $13.33 \%$ of the examined canned sardine and 13.33 of the examined frozen fish fillets are non-accepted samples due to the occurrence of AFB2 (FDA,2004). About $16.67 \%, 10 \%$ and $6.67 \%$ of the examined smoked herring samples, canned sardines and frozen fish fillet, respectively are unaccepted due to the incidence of AFG1 (FDA, 2004). Also $10 \%$ of the examined smoked herring, $3.33 \%$ of the examined canned sardines were rejected due to the occurrence of AFG2 (FDA, 2004). Whereas all the examined samples of frozen fish fillets were accepted.

Table 2 Levels of aflatoxins (B1, B2, G1 and G2) $(\mu \mathrm{g} / \mathrm{kg})$

\begin{tabular}{|c|c|c|c|c|}
\hline Fish products & AFB $1(\%)$ Mean \pm S.E* & AFB2 $(\%)$ Mean \pm S.E* & AFG1 (\%) Mean \pm S.E* & AFG2 $(\%)$ Mean \pm S.E* \\
\hline Smoked herring & $51.63 \pm 4.82$ & $37.29 \pm 3.75$ & $25.06 \pm 3.18$ & $16.22 \pm 1.39$ \\
\hline Canned sardines & $33.14 \pm 2.98$ & $20.81 \pm 3.02$ & $14.42 \pm 1.96$ & $11.79 \pm 0.92$ \\
\hline Frozen fish fillets & $19.76 \pm 2.21$ & $14.57 \pm 1.90$ & $9.65 \pm 1.32$ & $4.46 \pm 0.53$ \\
\hline
\end{tabular}

Table 3 Edibility of the examined fish products samples according to their levels of aflatoxins (B1, B2, G1 and G2) (n=30)

\begin{tabular}{lcccc}
\hline & $\begin{array}{c}\text { Unaccepted samples due to AFB1 } \\
(\%)\end{array}$ & $\begin{array}{c}\text { Unaccepted samples due to AFB2 } \\
(\%)\end{array}$ & $\begin{array}{c}\text { Unaccepted samples due to AFG1 } \\
(\%)\end{array}$ & $\begin{array}{c}\text { Unaccepted samples due to AFG2 } \\
(\%)\end{array}$ \\
\hline Smoked herring & 33.33 & 23.33 & 16.67 & 10 \\
Canned sardines & 23.33 & 13.33 & 6.67 & 10 \\
Frozen fish fillets & 16.67 & 13.33 & 3.33 \\
\hline
\end{tabular}

It is evident from data present in table (4) that $16.67 \%$ of smoked herring, $6.67 \%$ of canned sardines and $6.67 \%$ of frozen fish fillets were contaminated with Ochratoxin A. Totally Ochratoxin A present in $10 \%$ of the examined fish products samples. Whereas, the mean values of Ochratoxin A $(\mu \mathrm{g} / \mathrm{kg})$ were $6.52 \pm 0.74 \mu \mathrm{g} / \mathrm{kg}$ in the examined smoked herring samples, $5.60 \pm 0.61 \mu \mathrm{g} / \mathrm{kg}$ in the examined samples of canned sardines and $3.24 \pm 0.39 \mu \mathrm{g} / \mathrm{kg}$ in frozen fish fillets. All the examined frozen fish fillets were accepted but $6.67 \%$ of the examined smoked herring and $3.33 \%$ of the examined canned sardines were rejected due to their incidence of Ochratoxin A according to the permissible limits of FDA (2004).

Table 4 Incidence $(\%)$ and levels of Ochratoxin A $(\mu \mathrm{g} / \mathrm{kg})$ in the examined fish products samples $(n=30)$ and the edibility of the examined fish product samples according to their levels of Ochratoxin A.

\begin{tabular}{lccc}
\hline Fish products & $(\%)$ & Mean \pm S.E* & Unaccepted samples $(\%)$ \\
\hline Smoked herring & 16.67 & $6.52 \pm 0.74$ & 6.67 \\
Canned sardine & 6.67 & $5.60 \pm 0.61$ & 3.33 \\
Frozen fish fillets & 6.67 & $3.24 \pm 0.39$ & 0 \\
\hline
\end{tabular}

\section{DISCUSSION}

Mold contamination of fish and fish products may occur due to improper sanitation before and / or during processing, handling, transportation and storage (Hassan, 2003). Mold contaminations represent a great risk due to production of mycotoxins (Hassan et al., 2009). High levels of these mycotoxins cause liver cancer while, lower levels lead to liver diseases and organ damage (Yousef, 1998).

Nearly all the examined samples in this study were contaminated with molds that may be due to contamination of such fish products during manufacturing procedures starting from catching of fish, handling, processing, transportation, and storage until purchasing (El-Zahaby, 2007).

Exposure to low levels of aflatoxins can lead to suppression of the immune system, slowing the development of children and increasing susceptibility to infectious diseases, while the higher levels of aflatoxins can lead to liver failure and death (Strosnider et al., 2006). Aflatoxin B1 (AFB1) is a strong hepatocarcinogen that can contaminate agricultural commodities and lead to human hepatocellular carcinoma
(HCC). Aspergillus species can cause mycosis (Aspergillosis) as well as mycotoxicosis. In human, Aspergillus fumigatus was considered as the primary cause of pulmonary aspergillosis especially in immunesuppressed patients (Chang et al. 2004).

Poor hygienic measures in fish treating may lead to fish contamination with microorganisms such as fungi and also occurrence of Aspergillus flavus in the examined samples (Abd El-Maksoud et al., 2010).

From the obtained results there was a decrease in level of aflatoxin in frozen fish fillets followed by canned sardines and smoked herring. These results may be due to methods of processing, packaging, handling and storage. Packaging is important to prevent mold contamination and to avoid reabsorption of moisture from surrounding environment to the product. (Gopal and Shankar, 2011). Within the examined samples, canned sardines show little contamination than smoked herring as the can itself is strong enough to protect the product, decrease the level of contaminants and provide good keeping quality of the product.

Lower results were recorded by Adeboyotayo et al. (2006) who examined marketed smoked dried fish and found that the presence of aflatoxins was in concentrations between $(1.5 \mathrm{ppb}-8.1 \mathrm{ppb})$ in the examined samples and Akinyemi et al. (2011), who examined fifty smoked dried fish samples and found that aflatoxin concentration in the sample were between $(0.030-1.150 \mathrm{ppb})$.

Aflatoxin G2 showed similar incidence in the examined samples of smoked herring and canned sardine that was $13.33 \%$ while lower incidence was recorded in frozen fish fillets $(6.67 \%)$.

The repeated exposure to aflatoxins even in low levels can enhance susceptibility of the growing host to infection and tumor (Raisuddin et al., 1993). Within classical epidemiology, several studies have associated the occurrence of liver cancer with the estimated aflatoxin consumption in the diet (Li et al., 2001).

Oral consumption of $200 \pm 100 \mathrm{ppb}$ of crude aflatoxin (B1, B2, G1 and G2) can cause testicular degeneration (Sahay, 1993). Aflatoxins compounds are heat stable and show little degradation so they cannot be destroyed by cooking or heating whereas, pressure cooking may decrease the aflatoxin content by $83 \%$ (Park and Kim, 2006). 
The achieved results revealed that the predominant toxin was aflatoxin B1 followed by AFB2, AFG1 and AFG2. The highest records for all of the toxin types were determined in smoked herring while lower results were detected in frozen fish fillets. Thus, sampling is a vital procedure in analysis of contaminated food (Reiter et al., 2009).

OTA has been proved to be nephrotoxic, immunotoxic, teratogenic and hepatotoxic. Once OTA is introduced, it is impossible to be removed or decreased as it is moderately stable and not affected by heating (Monaci et al., 2005; schiavone et al., 2008).

The microbial level obtained in this study could be considered hazardous to consumers due to the presence of enterotoxigenic strains. This agreed with the reports of (Akande and Tobor, 1992; Adebayo-Tayo et al., 2008).

\section{CONCULSION}

The achieved results in this study revealed that smoked herring had the highest levels of aflatoxins (B1, B2, G1 and G2) and Ochratoxin A followed by canned sardine then frozen fish fillets. The examined fish products were subjected to contamination by different types of aflatoxins so that strict preventive measures must be applied to get out of or at least to minimize this contamination and its public hazard effect.

\section{REFERENCES}

1. Abdel-Maksoud, S. A.; El-Kuttan, A.A. and Mohammed, M.E. (2010): Mycological studies on smoked fish marketed in Dumyat with special references to public health importance. $10^{\text {th }}$ Sci. Vet. Med. Zag. Conference. Pp. 69-76.

2. Adam, M. A.; Tabana, Y. M.; Musa, K. B. and Sandai, D. A (2017): Effects of different mycotoxins on human, cell genome and their involvement in cancer (Review). Oncology Reports. 37(3): 1321-1336.

3. Adebayo-Tayo, B.C.; Onilude, A. A. and Patrick, U. G. (2008): Mycoflora of smoke - dried fishes sold in Uyo, Eastern Nigeria. World J. Agri. Sci., 4 (3) 346 - 350.

4. Akande, G.R. and J.G. Tobor, (1992): Improved utilization and increased availability of fishing products as an effective control of aggravated animal protein deficiency induced malnutrition in Nigeria Proceeding of the $10^{\text {th }}$ annual conference of the fisheries society of Nigeria. Pp: 18-31, and 230-234.

5. Akinyemi, A.A; Adejola, A.Q.; Qbasas, O. and Ezeri, G.N.O (2011): Aflatoxin in smoked dried fish sold in Abeokuta, Ogun State, South west Nigeria. Proceeding of the Environmental Management conference, Federal Univ. of Agri, Abeokuta, Nigeria.

6. Amnah, A.H. (2013): Removal of aflatoxin B1 from experimentally contaminated whole milk using a pool of probiotic strains of lactic acid bacteria and baker's yeast. New York Science J., 6(8): 84-90.

7. Association of Official Analytical Chemists "AOAC" (2000): Official Methods of the AOAC International Analysis. 13th Ed., Horwitz. W; (Ed.), Academic Press, Washington D.C, USA.

8. Ayolabi, C.I and Fagade, Ezekiel O. (2010): Mycological evaluation of smoked fish (Ethhmalosa fimbriata) from retail outlets in Ago-Iwoye, Ogunstate, Nigeria 3 (2): 64 - 68.

9. C`olovic, R.; Puvac`a, N.; Cheli, F.; Avantaggiato, G.; Greco, D.; Duragi'c, O.; Kos, J. and Pinotti, L. (2019): Decontamination of Mycotoxin contaminated Feed stuffs and Compound Feed. Toxins, 11,617.

10. Chang, P.K.; Bhatnagar, D. and Cleveland, T.E. (2004): Encyclopedia of food microbiology, Elsevier Ltd., London. Pp. 62-66
11. EL-Zahaby, D.I.M. (2007): Microbiological and chemical studies on some fish and fish products in Menoufia Governorate. M. V. Sc. thesis (Meat Hygiene and Control), Fac. Vet. Med. Menoufia. Egypt.

12. European Council "EC" (2006): The methods of sampling and analysis for the official control of the levels of mycotoxins in foodstuffs. Official Journal of the European Union, L70. Pp. 12-34.

13. Feldman, D.; Hoffman, R. and Simpson, J. (2003): The solution for data analysis and presentation graphics. 2nd Ed., Abacus Lancripts, Inc. Barkeley, CA, USA.

14. Food and Drug Administration "FDA" (2004): Worldwide regulation for mycotoxin in food and feed in 2003. Rome, 2004. FDA. Food and Nutrition. Pp. 81.

15. Fredrick S. J.; Immaculate J, and Patterson E, J.K. (2016): Aflatoxin Investigation on dried fish of Tuticorin, South East Coast of India-Journal of food borne and Zoonotic Diseases 3(4): 49-62.

16. Galvano, F., Galofaro, V., Ritieni, A., Bognanno, M., De Angelis, A. and Galvano, G. (2001): Survey of the occurrence of aflatoxin M1 in dairy products. Food Additives and Contaminants, 18: 644-646.

17. Gopal TS and Shankar CN (2011): Quality and safety of packaging materials for aquatic products. In C. Alasalvar, F. Shahidi, K. Miyashita and U. Wanasundara (Eds). Handbook of Seafood Quality, Safety and Health Applications. West Sussex: Blackwell publishing limited

18. Hassan, A.A. (2003): Detection of some mycotoxins and mycotoxins producing fungi in both macro and microenvironmental of diseased animals. 7th Sci. Cong. Egyptian Society for Cattle Diseases. Assiut, Egypt. Pp. 112-119

19. Hassan, A.A.; Wael M.T.; Abd El-Aziz, A.E. and Howayda, M.E. (2009): The hepatoprotective effect of dimethyl 4,4 dimethoxy 5,6,5,6- dimethylenedioxy biphenyl- dicarbxylate (D.D.B.) against liver injury induced by aflatoxin B1 in rates, Egypt. J. of Appl. Sci., 24 (9): 86-100.

20. Li, F.Q.; Yoshizawa, T.; Kawamura, S.; Luo, S.Y. and Li, Y.W. (2001): Aflatoxins and fumonisins in corn from the high - incidence area for human hepatocellular carcinoma in Guangxi, China. J. Agric. Food Chem., 49: 4122-4126.

21. Monaci, L., Palmisano, F., Matella, R., and Tantillo, G. (2005): Determination of Ochratoxin A at part-per-trillion level Italian salami by immunoaffinity cleanup and highperformance liquid chromatography with fluorescence detection. J. Chromatography. A, 1090: 184-187.

22. Park, J.W. and Kim Y.B. (2006): Effect of pressure cooking on aflatoxin B1 in rice. J. Agri. and Food Chem., 54: 24312435.

23. Raisuddin, S.; Singh, K.P; Zaidi, S.; Paul, B. and Ray, P (1993): Immunosuppressive effects aflatoxin in growing rats. Mycopathologia, 124(3): 189-194.

24. Reiter, E.; Zentee, J. and Razzazi, E. (2009): Review on sample preparation strategies and method used for analysis of aflatoxins in food and feed. Molecular Nutrition and Food Research. 53,(4): 508-524.

25. Richard, J.L. (2007): Some major mycotoxins and their mycotoxicosis an overview. Int. Journal Food Microb.119: 310 .

26. Sahay, M. (1993): Aflatoxin induced testicular degeneration and decreased meiotic index in rattus norvegicus. Cytobio., 75: 302-303.

27. Schiavone, A., Cavallero, C., Girotto, L., Pozzo, L. Antoniazzi, S. and Cavallarin, L. (2008): A survey on the occurrence of Ochratoxin A in feeds and sera collected in conventional and organic poultry farms in Northern Italy. Italian J. Animal Sci., 7: 495-503.

28. Shewan, J.M. (2000): The Microbiology of sea water fish. In fish as food. Ed by B. Borgstrom, I New York Academic press., pp:487.

29. Strosnider, H., Azziz-Baumgartner, E., Banziger, M., Bhat, R.V., Breiman, R., Brune, M.N., DeCoek, K., Dilley, A., Groopman, J. and Hell, K. (2006): Workgroup report public health strategies for reducing aflatoxin exposure in developing countries. Environmental health perspectives, 1898-1903 
30. Tolosa, J.; Barba, F. J.; Font, G. and Ferrer, E. (2019): Mycotoxin Incidence in some fish products: QuEChERS Methodology and Liquid Chromatography Linear Ion Trap Tandem Mass Spectrometry Approach. Molecules. 24(3): 527.
31. Youssef, H.H.E. (1998): Mycological status of Moloha, smoked herring and frozen mackerel fish in Assiut province. M. V. Sc. Thesis, Dept. Food Control, Fac. Vet. Med., Assiut University, Egypt. 